\title{
PERSPECTIVE OPEN \\ Urban atmospheric chemistry: a very special case for study
}

\author{
Roy M. Harrison ${ }^{1,2}$
}

Studies of the chemistry of the urban atmosphere provide special challenges which arise from the high density of emissions, strong concentration gradients and relatively high pollutant concentrations. In contrast to the regional and global atmosphere, local dispersion processes play a much larger role in determining atmospheric concentrations and also have a substantial effect on chemical transformations. On the other hand, residence times in the urban atmosphere are relatively short, hence limiting the range of chemical reaction processes which are significant. Some key species such as the hydroxyl radical have different predominant source processes in the urban and the regional atmosphere. A case is made that the differences are so large that urban atmospheric chemistry needs to be given special treatment and cannot simply be considered as subtlely different from regional and global atmosphere studies.

npj Climate and Atmospheric Science (2018)1:20175; doi:10.1038/s41612-017-0010-8

\section{INTRODUCTION}

By far the main emphasis of research in past decades in atmospheric chemistry has been on the global and regional atmosphere. Much the same is true of research in meteorology and atmospheric physics which has centred mainly on issues of global climate and regional weather. Such research is extremely important if we are to understand fully the working of atmosphere and predict the impacts of anthropogenic perturbations upon the future composition and climate of our planet's atmosphere. However, it ignores the fact that a large percentage of global population live in cities and that cities present a very special case as far as atmospheric composition and physics are concerned. Current chemistry-transport models applied to the mesoscale do not have sufficient resolution to describe adequately urban processes, or if nested to very high spatial resolution do not have suitable input data to reflect spatial gradients in concentation reliably. Although physical models of the urban atmosphere have been developed, they are often limited by the sparcity of the observations which are needed to develop their parameterisations and validate their outputs.

Meteorological networks typically avoid measurements within urban areas despite (or perhaps because of) the greater complexity of meteorological phenomena within built-up areas compared to the open countryside. Measurements of composition are typically limited to the classical air pollutants (sulphur dioxide, oxides of nitrogen, carbon monoxide, ozone and particulate matter) and are typically made with a very low spatial density. Consequently, scientific advances requiring observations have generally depended upon deployment of specialist instrumentation during short campaigns. Research programmes such as REPARTEE (London), ${ }^{1}$ MEGAPOLI $^{2}$ (Paris), ClearfLo (London) ${ }^{3}$ and CalNex ${ }^{4}$ have been required in order to gain enhanced understanding of urban atmospheric chemistry. There have also been a few high density urban meteorological networks developed such as the Birmingham Urban Climate Laboratory. ${ }^{5}$ Such activities are, however, typically expensive to maintain and have often continued only for a relatively short time.

\section{WHAT DISTINGUISHES URBAN AREAS FROM REGIONAL PROCESSES?}

Figure 1 illustrates schematically the distribution of trafficgenerated pollution across a city. The main features characterising air pollution phenomena in urban areas which distinguish them from regional processes include the following:

- High levels of primary emissions. Historically these were domestic emissions, and in some less developed countries, these remain a major source. Nowadays, the high volumes of road traffic within urban areas often dominate the urban air pollution climate.

- Strong concentrations gradients. Because of the localisation of sources such as emissions from major highways and the presence of suburban areas of relatively lower emissions and urban parkland, there are typically much stronger gradients in concentrations within urban areas than in the surrounding rural locations. Such gradients exist both in the horizontal and vertical dimensions.

- Importance of mixing processes. Because of the strong concentration gradients, pollutant concentrations determined by fast chemical reactions are often heavily influenced by the rate of atmospheric mixing processes which can vary very substantially according to wind speed and atmospheric stability.

- Typically higher aerosol surface area. Concentrations of particulate matter are typically elevated within urban areas hence providing a larger surface area available for heterogeneous chemical processes.

- Urban surfaces and heat island. Urban mixing processes are influenced by greater surface roughness caused by the presence of buildings. The urban heat island effect can lead to enhanced and temporally extended convection, and to deeper mixed layers than over typical rural surfaces.

\footnotetext{
${ }^{1}$ Division of Environmental Health and Risk Management, School of Geography, Earth and Environmental Sciences, University of Birmingham, Edgbaston, Birmingham B15 2TT, United Kingdom and ${ }^{2}$ Department of Environmental Sciences/Center of Excellence in Environmental Studies, King Abdulaziz University, PO Box 80203 , Jeddah 21589, Saudi Arabia

Correspondence: Roy M. Harrison (r.m.harrison@bham.ac.uk)
}

Received: 30 March 2017 Revised: 23 October 2017 Accepted: 24 October 2017

Published online: 09 January 2018 


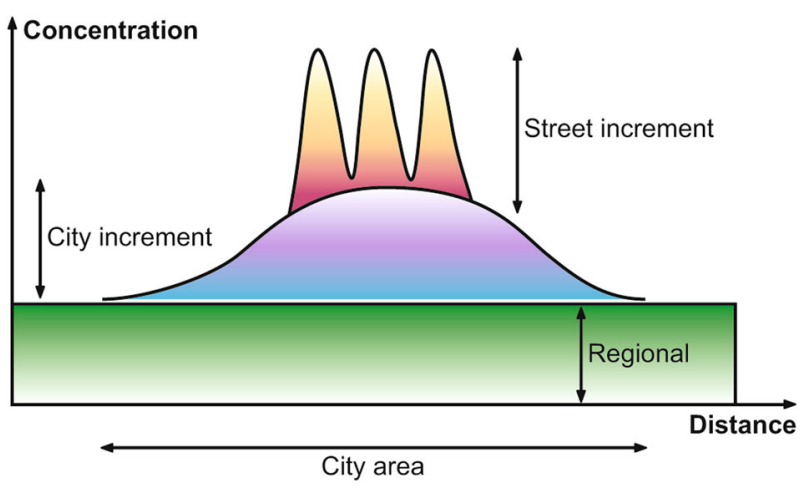

Fig. 1 Schematic profile of traffic-generated pollution across a city

\begin{tabular}{|c|c|c|}
\hline Town/City & External dimensions $(\mathrm{km})$ & Advection time $(h)^{a}$ \\
\hline Reading & $12.5 \times 7.5$ & $0.3-1.4$ \\
\hline Manchester & $25 \times 20$ & $0.6-3.1$ \\
\hline Birmingham & $30 \times 15$ & $0.6-3.1$ \\
\hline London & $52.5 \times 40$ & $1.3-6.4$ \\
\hline
\end{tabular}

${ }^{a}$ for wind speeds of $2-10 \mathrm{~m} \mathrm{~s}^{-1}$

Table 2. Lifetimes with respect to reaction with $\mathrm{OH}$

\begin{tabular}{ll}
\hline Compound & ${\text { Lifetime }(\mathrm{h})^{\mathrm{a}}}^{\mathrm{a}}$ \\
\hline Isoprene & 2.7 \\
$\alpha$-Pinene & 5.2 \\
i-Butene & 5.4 \\
But-1-ene & 8.8 \\
Decane & 24 \\
Ethylbenzene & 39 \\
Toluene & 47 \\
n-Butane & 110 \\
Benzene & 210 \\
Ethane & 1080 \\
Nitrogen dioxide & 25 \\
Sulphur dioxide & 309 \\
\hline a $[\mathrm{OH}]=1 \times 10^{6} \mathrm{~cm}^{-3}$ & \\
\hline
\end{tabular}

- Dominance of rapid chemical processes. Timescales for chemical reactions are typically much shorter within the urban atmosphere in comparison to the much longer residence times of pollutants in the regional atmosphere. As illustrated by Table 1, at typical wind speeds, residence times of pollutants in the urban atmosphere are only a few hours at most, limiting the extent to which many chemical reactions can proceed. This is exemplified by Table 2 which shows lifetimes of a range of compounds with respect to reaction with the key oxidant, the hydroxyl radical. It should be recognised that data in Tables 1 and 2 is solely illustrative and that under stagnant conditions residence times could be very much greater than those in Table 1, and that some chemical reactions such as that between nitric oxide and ozone are much faster than those shown in Table 2.

Figures 1 and 2 (deriving conceptually from ref. $\left.{ }^{6}\right)^{6}$ exemplify the elevation in pollutant concentrations which is typically found within cities. Roadside concentrations of traffic-generated pollutants

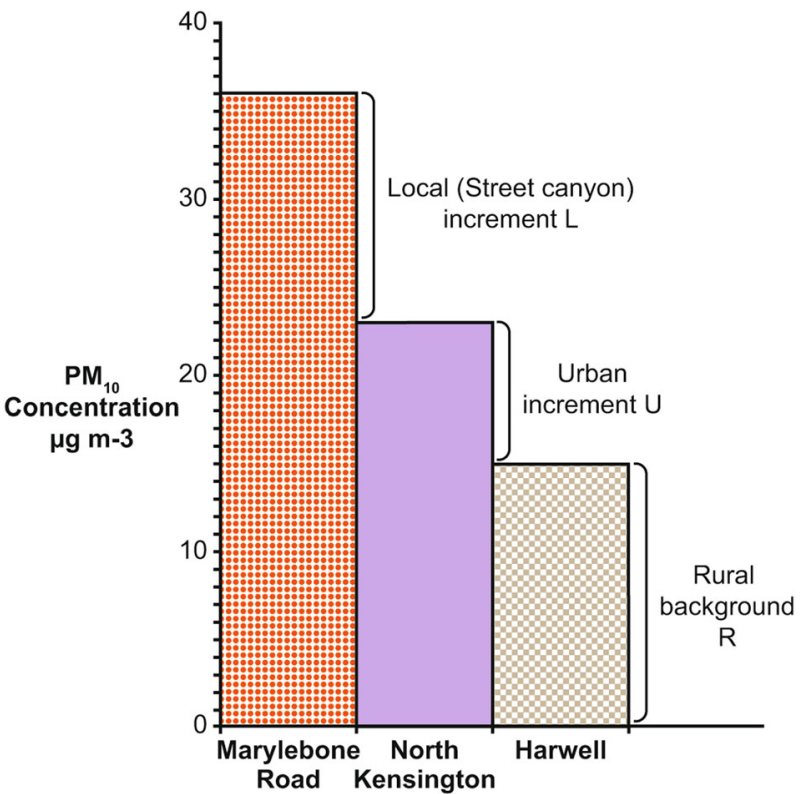

Fig. 2 Median concentrations of $\mathrm{PM}_{10}$ at roadside, urban background and rural sites (based upon ref. ${ }^{6}$ )

Table 3. Average concentrations (annual mean) at roadside and urban background sites in London, and in the rural background

\begin{tabular}{llll}
\hline Pollutant & $\begin{array}{l}\text { Marylebone } \\
\text { Road } \\
\text { (roadside) }\end{array}$ & $\begin{array}{l}\text { North Kensington } \\
\text { (urban } \\
\text { background) }\end{array}$ & Rural \\
\hline Carbon monoxide $\left(\mathrm{mg} \mathrm{m}^{-3}\right)$ & 0.51 & 0.32 & \\
Nitrogen dioxide $\left(\mu \mathrm{g} \mathrm{m}^{-3}\right)$ & 88 & 32 & 4 \\
Sulphur dioxide $\left(\mu \mathrm{g} \mathrm{m}^{-3}\right)$ & 9 & 2 & 1 \\
Ozone $\left(\mu \mathrm{g} \mathrm{m}^{-3}\right)$ & 15 & 42 & 65 \\
$\mathrm{PM}_{10}\left(\mu \mathrm{g} \mathrm{m}^{-3}\right)$ & 24 & 20 & 15 \\
$\mathrm{PM}_{2.5}\left(\mu \mathrm{g} \mathrm{m}^{-3}\right)$ & 16 & 11 & 9 \\
Particle number $\left(\mathrm{cm}^{-3}\right)$ & 26,300 & 9100 & 4000 \\
Black carbon $\left(\mu \mathrm{g} \mathrm{m}^{-3}\right)$ & 6.6 & 1.4 & 0.46 \\
\hline Data for 2016 & & & \\
\hline
\end{tabular}

typically well exceed those in the urban background which in turn exceeds concentrations measured in surrounding rural areas. However, as shown in Fig. 1, the traffic increment on concentrations is highly non-uniform and can cause substantial local elevations in some locations. Table 3 exemplifies the strong gradients observed for many pollutants between the urban roadside and both the urban background and local rural environment. This is most notable for oxides of nitrogen, particle number and black carbon, all of which have a strong road traffic source.

Dry deposition processes can also have an influence upon urban concentrations and their spatial distributions. Typical lifetimes associated with dry deposition of particles are illustrated in Table 4. However, for aerosols, it is only for the relatively large particles and shallow mixing depths that lifetimes are sufficiently short to create substantial spatial gradients.

As noted above, roadside pollutant concentrations are strongly elevated and urban street canyons provide an environment of more concentrated pollutants with typical timescales estimated in Table 5 as between 3.8 and 14 minutes dependent upon aspect ratio, giving sufficient time only for the more rapid chemical reactions to have a significant effect. Photolysis rates of pollutants 
Table 4. Lifetimes with respect to dry deposition for particles of various sizes as a function of mixing layer depth

\begin{tabular}{lllll}
\hline Diameter & $V_{\mathrm{g}}\left(\mathrm{cm} \mathrm{s}^{-1}\right)$ & \multicolumn{3}{l}{ Lifetime $\left(\right.$ hours ${ }^{\mathrm{a}}$} \\
\cline { 3 - 5 } & & $\mathrm{H}=10 \mathrm{~m}$ & $\mathrm{H}=100 \mathrm{~m}$ & $\mathrm{H}=1000 \mathrm{~m}$ \\
\hline $10 \mu \mathrm{m}$ & 0.5 & 0.56 & 5.6 & 56 \\
$5 \mu \mathrm{m}$ & 0.3 & 0.93 & 9.3 & 930 \\
$1 \mu \mathrm{m}$ & 0.1 & 2.8 & 28 & 280 \\
$0.1 \mu \mathrm{m}$ & 0.1 & 2.8 & 28 & 280 \\
\hline a For roughness length $=10 \mathrm{~cm}$ & &
\end{tabular}

Table 5. Residence times in street canyons

\begin{tabular}{lll}
\hline Aspect ratio $(\mathrm{h} / \mathrm{b})$ & $\tau / \mathrm{T}$ & $\tau(\mathrm{min})^{1}$ \\
\hline 0.5 & 54.4 & 4.5 \\
1.0 & 45.5 & 3.8 \\
2.0 & 167.7 & 14.0 \\
\hline${ }^{1}$ For $\mathrm{T}=\mathrm{h} / \mathrm{u}=25 \mathrm{~m} / 5 \mathrm{~m} \mathrm{~s}^{-1}$ & [h = building height; $\mathrm{b}=$ canyon width; $\mathrm{u}=$ \\
wind speed] & & \\
Based upon Cheng et al. ${ }^{26}$ & & \\
\hline
\end{tabular}

such as nitrogen dioxide are sufficiently rapid that this can affect spatial distributions within street canyons.?

\section{CHEMICAL REACTION PROCESSES IN THE URBAN ATMOSPHERE}

For many years, the drivers of hydroxyl radical formation in the urban atmosphere were assumed to be the same as that in the rural atmosphere where formation is predominantly through the photolysis of ozone and reaction of the resultant singlet atomic oxygen with water vapour (see Box 1). However, the experimental measurements of Dwayne Heard and colleagues using the FAGE technique in the urban atmosphere of Birmingham, UK (Fig. 3), showed that winter concentrations of hydroxyl were about $50 \%$ of summer concentrations whereas scaling based upon ozone photolysis predicts concentrations only around $5 \%$ of summer concentrations. ${ }^{8,9}$ This led to a realisation that other sources of hydroxyl are more important in the urban polluted atmosphere and these include photolysis of nitrous acid and formaldehyde as well as the decomposition of the Criegee biradical intermediate formed from ozone-alkene reactions ${ }^{10}$ (see Box 1$)$. Such processes are typically included in Chemistry-Transport Models (e.g., the RADM2 scheme ${ }^{11}$ used in the WRF-Chem model), but depend critically upon reliable predictions of $\mathrm{HONO}$ and $\mathrm{HCHO}$ concentrations. The former are influenced by heterogeneous chemical processes on ground surfaces ${ }^{12}$ which are not included in the model. Both fine-scale and coarse-scale resolution models perform poorly in prediction of ozone and $\mathrm{PM}_{10}$ concentrations, ${ }^{13,14}$ with fine scale models not clearly exhibiting superior skill to coarse grid models. $^{14}$

While many daytime oxidation processes are dominated by the hydroxyl radical, its concentrations at night typically fall to rather low levels while the nitrate radical which is destroyed by photolysis can build up to higher concentrations during nighttime hours. Box 2 shows how nitrate radical is formed from the reaction of nitrogen dioxide with ozone and is likely to take place in elevated layers of the atmosphere as nitrogen dioxide emitted or formed close to the surface mixes with ozone-rich air from aloft to form the nitrate radical $^{15}$ which will not readily form close to ground-level because of its reaction with nitric oxide which is a
Box 1 Hydroxyl radical formation
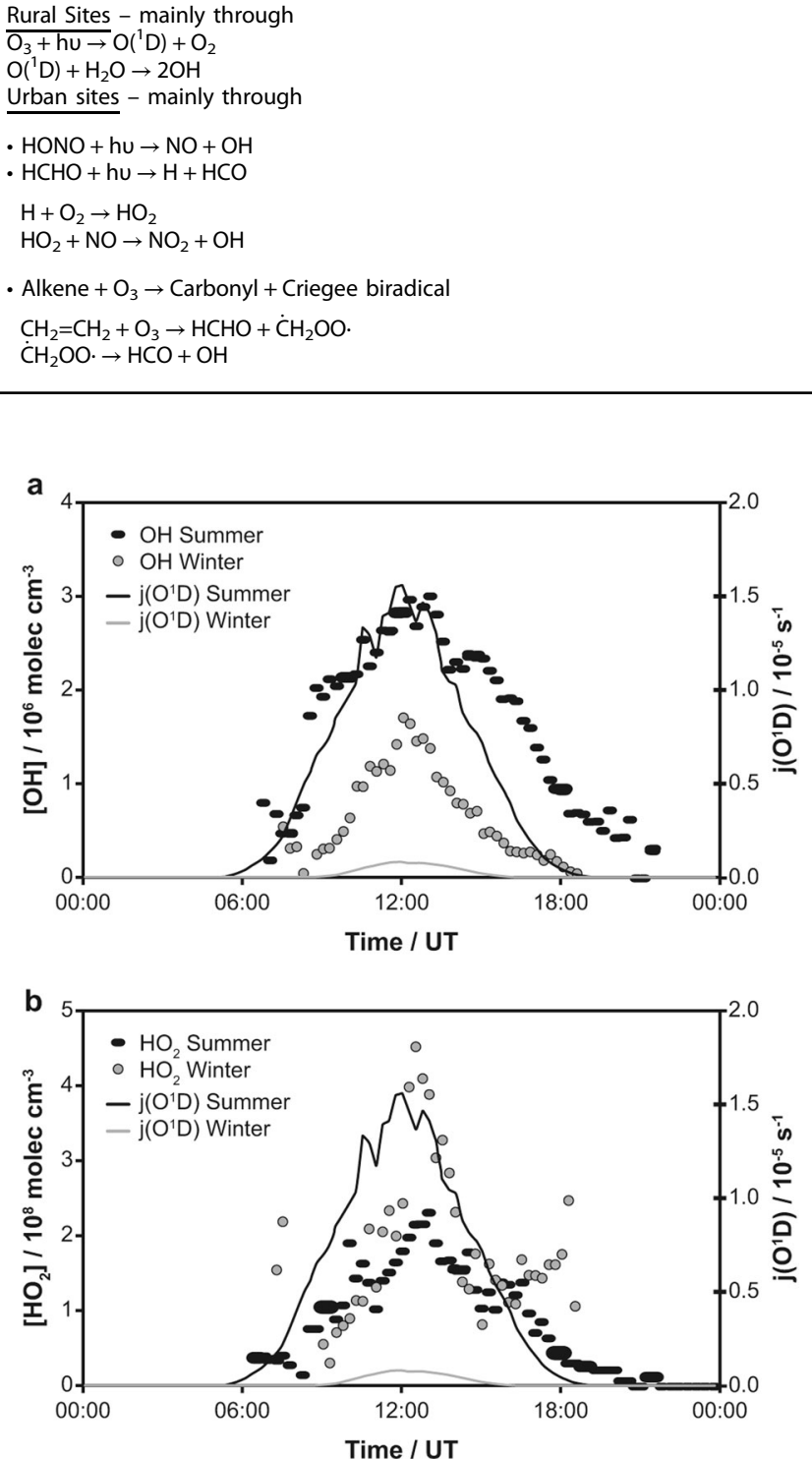

Fig. 3 Seasonal influence upon urban $\mathrm{OH}$ radical concentrations. Diurnal variation of $\mathbf{a} \mathrm{OH}$ and $\mathbf{b} \mathrm{HO}_{2}$ for the summer and winter campaigns, together with the corresponding variation of the rate of $\mathrm{O}_{3}$ photolysis, $j\left(\mathrm{O}^{1} \mathrm{D}\right)^{8}$

direct emission from road traffic. Box 2 shows the chemical reactions involved as well as citing some predicted and measured concentrations of the nitrate radical. These processes can ultimately lead to the formation of nitric acid vapour which participates in the formation of nitrate aerosol. Since there are major urban sources of nitrogen dioxide and also of ammonia from waste water systems and road traffic, ${ }^{16}$ it is anticipated that nitrate concentrations in the urban atmosphere most probably exceed those in surrounding rural areas, but data is currently rather sparse. Dall'Osto et al. ${ }^{17}$ used single particle mass spectrometry to demonstrate in near real time the semi-volatility of ammonium nitrate whose concentrations increased at nighttime as temperatures fall and relative humidity increases while subsequently evaporating during the higher temperature and lower humidity conditions of daytime. 


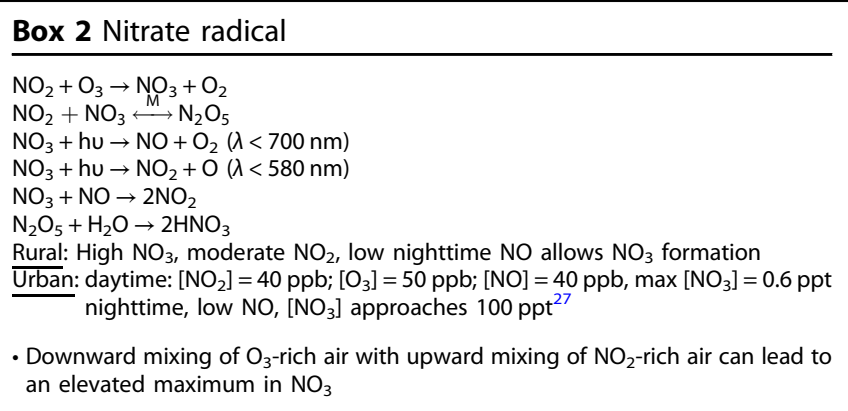

\section{CONSEQUENCES OF URBAN ATMOSPHERIC PROPERTIES}

The points raised above lead to a number of conclusions:

It matters critically where you measure (in the horizontal and the vertical). Unlike the rural atmosphere, which is typically rather well mixed, the strong spatial gradients in the urban atmosphere can lead to substantial differences in concentrations over small distance scales. It is important to establish the range over which any individual measurement point is representative of the locality. Measurements on the BT Tower in London during the ClearfLo campaign $^{3}$ defined the typical mixing depths in London and showed how they differed substantially from those in surrounding rural areas, and measurements in the REPARTEE campaigns on the BT Tower in London showed the crucial effect of mixing depth on particle number size distributions. ${ }^{1}$ In a well mixed boundary layer, traffic-generated nucleation mode particles were measured on the Tower, but at smaller mixing depths, only Aitken and accumulation mode particles deriving mainly from regional transport were seen.

It matters when you measure-effects of diurnal variation of sources and atmospheric stability. There are marked diurnal variations in both traffic volumes, wind speed and atmospheric stability which lead to a characteristic diurnal variation of concentrations of traffic-generated pollutants in the urban atmosphere. This typically shows a major peak associated with the morning rush hour and a longer-lived peak in the evening associated with both increased traffic volumes, reduced wind speeds and an increasingly stable atmosphere. Mixing depths are typically substantially greater during daytime than nighttime and consequently sampling air aloft on a tower, the air sampled will probably be from within the surface mixed layer during daytime, but from advected regional air separated by an inversion from the surface layer at night.

Concentrations of reactive pollutants may be determined by either mixing or chemistry, or both. The mixing of ozone-rich urban air from aloft with polluted air from lower levels can have profound influences through dilution of the nitrogen oxides emitted by traffic at ground level and depletion of ozone by chemical reaction with nitric oxide. Consequently, such processes tend to determine the vertical gradients and ground-level concentrations of both oxides of nitrogen and ozone. An inadequate description of such processes probably explains how coarse grid models in particular fail to predict urban ozone concentrations well. ${ }^{14}$ As noted above, formation of the nitrate radical is likely to occur in elevated layers since it requires the co-existence of nitrogen dioxide and ozone in order for the correct chemistry to take place. Nitrous acid (HONO) is a pollutant which is emitted from road traffic but is also photolysed in the atmosphere on a timescale of minutes. ${ }^{18}$ Consequently, the distribution of concentrations can reflect both the traffic emissions of HONO and creation from other sources as well as the photolytic loss.

Some more reactive species may be important in urban areas but have decayed before reaching the rural atmosphere. The lifetime of some species in the atmosphere is typically only seconds or minutes and consequently such species are likely to be destroyed by chemical reaction or photolysis before advecting far from an urban source. Nitrous acid is an example of a pollutant with urban sources which is readily photolysed and consequently strong urban-to-rural gradients in its concentration are observed. Nitric oxide is the major part of oxides of nitrogen emissions from road traffic and typically comprises a substantial percentage of the $\mathrm{NO}_{\mathrm{x}}$ in the urban atmosphere. However, due to dilution and oxidation by ozone, rural oxides of nitrogen are typically dominated by nitrogen dioxide with only modest amounts of nitric oxide forming through photolysis of $\mathrm{NO}_{2}$.

Work in London has demonstrated the semi-volatility of nucleation mode particles from road traffic ${ }^{15,19}$ which comprise mainly semi-volatile organic compounds deriving from unburned diesel fuel and lubricating oil. ${ }^{20}$ Such particles are liable to shrink by evaporation as they advect into cleaner air within the urban environment and are largely absent from particle size distributions measured at surrounding rural sites. Measurements in Barcelona have provided evidence for the contribution of particles formed by regional nucleation processes ${ }^{21,22}$ and there appear to be contributions both from advection of particles formed outside of the city as well as a separate population of particles which form within the Barcelona atmosphere. ${ }^{22}$ It is notable that the abundance of nucleation mode particles caused by regional nucleation processes is spatially variable within Barcelona, with formation being suppressed at roadside sites by the substantial condensation sink provided by the road traffic-generated aerosol. ${ }^{22}$ Reliable knowledge of that condensation sink is a key factor in prediction of sulphuric acid vapour concentrations, and the rate of formation of new particles by nucleation. ${ }^{23}$

Reliable emissions inventories are essential. Errors in source emissions inventories relating to the spatial and temporal distribution of emissions (as opposed to systematic under- or over-estimation of emissions) cause greater problems in fine resolution urban models than in coarse resolution models where there is a possibility for them to be smoothed out by the greater spatial averaging. Incorrect spatial allocation of emissions can lead to substantial errors in prediction of local concentrations within urban areas where sources can vary over small distances.

Simply increasing the spatial resolution of chemistry-transport models is not sufficient to give better predictions. While it might be argued that increasing the grid resolution of rural models alone might lead to better prediction of urban processes, this will not be effective for a number of reasons. Firstly, the heat fluxes, turbulence and mixing depths differ in urban areas from those of the surrounding rural area and need to be reflected adequately in the model. Even then, if the grid resolution is very high, emissions data are unlikely to be of sufficient resolution to match the model grid, and hence concentration gradients due to inhomogeneous sources will not be well described. Not only atmospheric mixing, but also chemical processes are affected by land surface types, and a downscaled rural model will not reflect this. Also, simply increasing the grid resolution will not allow inclusion of street canyon processes which delay the mixing of pollutants into the wider atmosphere and allow a greater degree of processing at elevated concentrations. Consequently, there is a need for custom-built chemistry-transport models, carefully designed to simulate the urban atmosphere, rather than downscaling of large domain models by increased grid resolution. This needs to be accompanied by higher resolution physical and chemical measurements, so as to maximise the value of such models.

\section{CONCLUSIONS}

Conventional knowledge of global and regional atmospheric chemistry is not sufficient to predict the behaviour of pollutants in the urban atmosphere. As model resolution is progressively improving, large domain models will increasingly be able to better resolve the urban atmosphere but will need to reflect the 
differing pollution climate and physical properties of the urban atmosphere in order to make reliable predictions. There is a pressing need for reliable estimates of pollutant concentrations and spatial distributions for use in epidemiological studies, but the widespread use of land-use regression modelling techniques ${ }^{24}$ in preference to Chemistry-Transport Models (CTMs) may be a reflection of the poor predictive capability of CTMs in urban areas, which in part reflects weaknesses in their dynamics and chemistry schemes. There is a need to tackle this problem by building new models incorporating specifically urban forms and processes, as opposed to continual downscaling of coarse resolution rural models.

While there remains a substantial overlap between processes occurring in large scale atmospheric processes and those on the smaller urban scale, the differences are sufficient to justify regarding urban atmospheric science as a very special case which cannot be addressed reliably by a simple downscaling of larger scale processes.

It is a welcome development that the recent National Academies report on Tropospheric Chemistry ${ }^{25}$ gives an acknowledgement of the importance of urban processes, but unfortunately it fails to give adequate emphasis to the special character of urban processes.

Data availability statement

The datasets generated during and/or analysed during the current study are available from the corresponding author on reasonable request.

\section{AUTHOR CONTRIBUTIONS}

R.H. conceived the paper and was responsible for the preparation of the manuscript.

\section{ADDITIONAL INFORMATION}

Competing interests: The author declares no competing financial interests.

Publisher's note: Springer Nature remains neutral with regard to jurisdictional claims in published maps and institutional affiliations.

Change history: The original version of this Article had an incorrect Article number of 5 and an incorrect Publication year of 2017. These errors have now been corrected in the PDF and HTML versions of the Article.

\section{REFERENCES}

1. Dall'Osto, M. et al. Atmospheric chemistry and physics in the atmosphere of a developed megacity (London): an overview of the REPARTEE experiment and its conclusions. Atmos. Phys. Chem. 12, 3065-3114 (2012).

2. Baklanov, A. et al. MEGAPOLI: concept of multi-scale modelling of megacity impact on air quality and climate. Adv. Sci. Res. 4, 115-120 (2010).

3. Bohnenstengel, S. I. et al. Meteorology, air quality, and health in London: the ClearfLo project. Amer. Meteor. Soc. 779-804. https://doi.org/10.1175/BAMS-D-1200245.1 (2015).

4. Ryerson, T. B. et al. The 2010 California research at the Nexus of air quality and climate change (CalNex) field study. J. Geophys. Res. 118, 5830-5866 (2013).

5. Chapman, L. et al. The birmingham urban climate laboratory. An open meteorological test bed and challenges of the Smart City. Am. Meteorol. Soc. 1545-1560. https://doi.org/10.1175/BAMS-D-13-00193.1 (2014).

6. Charron, A., Harrison, R. M. \& Quincey, P. What are the sources and conditions responsible for exceedences of the $24 \mathrm{~h}$ PM10 limit value $(50 \mu \mathrm{g} \mathrm{m}-3)$ at a heavily trafficked London site? Atmos. Environ. 41, 1960-1975 (2007).

7. Grawe, D., Cai, X.-M. \& Harrison, R. M. Large eddy simulation of shading effects on $\mathrm{NO} 2$ and $\mathrm{O} 3$ concentrations with an idealised street canyon. Atmos. Environ. 41, 7304-7314 (2007).
8. Harrison, R. M. et al. Measurement and modelling of air pollution and atmospheric chemistry in the UK West Midlands conurbation: Overview of the PUMA consortium project. Sci. Tot. Environ. 360, 5-25 (2006).

9. Heard, D. E. et al. High levels of the hydroxyl radical in the winter urban troposphere. J. Geophys. Res. Letts. 31, L18112 (2004).

10. Atkinson, R. \& Aschmann, S. M. OH radical production from the gas-phase reactions of $\mathrm{O} 3$ with a series of alkenes under atmospheric conditions. Environ. Sci. Technol. 27, 1357-1363 (1993).

11. Stockwell, W. R., Middleton, P. \& Chang, J. S. The second generation regional acid deposition model chemical mechanism for regional air quality modeling. J. Geophys. Res. 95, 16343-16367 (1990).

12. Harrison, R. M., Peak, J. D. \& Collins, G. M. Tropospheric cycle of nitrous acid. J. Geophys. Res. 101, 14429-14439 (1996).

13. Thunis, P. et al. Analysis of model responses to emission-reduction scenarios within the CityDelta project. Atmos. Environ. 41, 208-220 (2007).

14. Vautard, R. et al. Evaluation and intercomparison of ozone and PM10 simulations by several chemistry transport models over four European cities within the CityDelta project. Atmos. Environ. 41, 173-188 (2007).

15. Harrison, R. M., Jones, A. M., Beddows, D. C. S., Dall'Osto, M. \& Nikolova, I. Evaporation of traffic-generated nanoparticles during advection from source. Atmos. Environ. 125, 1-7 (2016).

16. Reche, $\mathrm{C}$. et al. Urban NH3 levels and sources in a Mediterranean environment Atmos. Environ. 57, 153-164 (2012).

17. Dall'Osto, M., Harrison, R. M., Coe, H., Williams, P. I. \& Allan, J. D. Real time chemical characterization of local and regional nitrate aerosols. Atmos. Chem. Phys. 9, 3709-3720 (2009).

18. Crilley, L. et al. On the interpretation of in situ HONO observations via photochemical steady state. Faraday Discuss. https://doi.org/10.1039/C5FD00224A (2016).

19. Dall'Osto, M. et al. Remarkable dynamics of nanoparticles in the urban atmosphere. Atmos. Chem. Phys. 11, 6623-6637 (2011).

20. Alam, M. S. et al. The characterisation of diesel exhaust particles-composition, size distribution and partitioning. Faraday Discuss. 189, 69-84 (2016).

21. Dall'Osto, M. et al. Urban aerosol size distributions over the Mediterranean city of Barcelona, NE Spain. Atmos. Chem. Phys. 12, 10693-10707 (2012).

22. Dall'Osto, M. et al. On the spatial distribution and evolution of ultrafine particles in Barcelona. Atmos. Chem. Phys. 13, 741-759 (2013).

23. Kulmala, M. et al. On the formation, growth and composition of nucleation mode particles. Tellus 53B, 479-490 (2001).

24. Hoek, G. et al. A review of land-use regression models to assess spatial vriaton of outdoor air pollution. Atmos. Environ. 42, 7561-7578 (2008).

25. Committee on the Future of Atmospheric Chemistry Research, Board on Atmospheric Sciences and Climate (2016) Division on Earth and Life Studies \& National Academies of Sciences, Engineering and Medicine. The Future of Atmospheric Chemistry Research: Remembering Yesterday, Understanding Today, Anticipating Tomorrow. https://www.nap.edu/cover/23573/450.

26. Cheng, W. C., Liu, C.-H. \& Leung, D. Y. C. Computational formulation for the evaluation of street canyon ventilation and pollutant removal performance. Atmos. Environ. 42, 9041-9051 (2008).

27. Seinfeld, J. H. \& Pandis, S. N. Atmospheric Chemistry and Physics. (John Wiley \& Sons, New York, 1998).

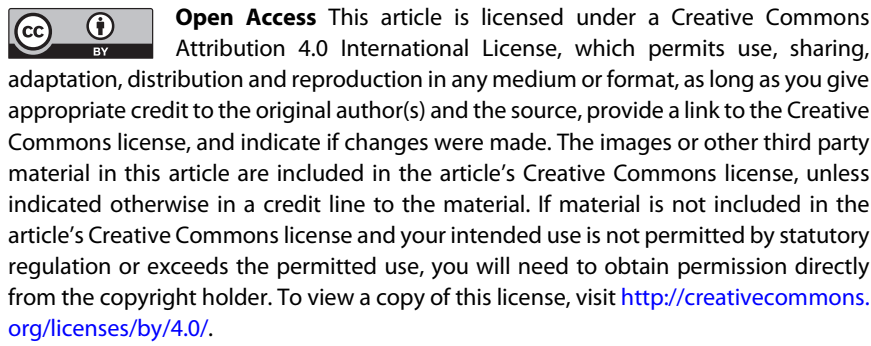

(c) The Author(s) 2018 